UDC 621.391

V.I. TIKHONOV, dr. of techn. sciences, professor "ONAT", Odessa

\title{
PIECEWISE LINEAR PHASE MODULATION FOR TERNARY DATA CODING IN COHERENT WIRELESS CHANNEL
}

The paper introduces the novel method of combined time-frequency successive symbol coding in a packet based radio channel, which is performed due to continuous phase modulation by piecewise linear functions. The first layer of multilayered symbol presentation with ternary digits described. This method improves dynamic performance adaptation of the channel and extends its scalability. Figs.: 1. Refs.: 15 titles.

Keywords: symbol coding, phase modulation, multilayered symbol presentation, dynamic performance adaptation.

The problem statement. The evolution of wireless networks started from analogue NMT-450 (1981) and goes on to advanced 4G-decisions. However, the " $4 \mathrm{~g}$ " term is not explicitly determined yet [1]. There are at least three " $4 g$ " term used: the ITU approved 4G standard [2], the 4G commercial brand (so called circuit switch fall back [3]), and pure packet switched oneradio access based on voice over LTE technology (VoLTE). Some experts consider LTE promising physical layer platform for future wireless networks [4]. Compare to $1 \mathrm{G}-3 \mathrm{G}$ mobile systems, the LTE implements a set of core novel ideas: a) coherent radio-communication channel with I/Q-modulation in contrast to legacy amplitude manipulation; b) combined time/frequency resource scheduling of radio channel access based on the orthogonal frequency division multiplexing (OFDM) within sampling intervals [5]; c) combined circuit/packet switching technique on the data link layer of radio access implemented due to the regular LTE-frames circulating with $100 \mathrm{~Hz}$-frequency between the evolved base station node (eNB) and associated user equipment entities (UEs) of mobile network cell; d) all over IP service provision, including voice communication and signaling, according to IMS concept (3GPP, 2008 [6]). The OFDM method is a core feature of LTE specification; it enhances the ether bandwidth utilization and its spectral efficiency, unlike legacy code division multiple access (CDMA) in 3G network. Though, the OFDM multiplexing faces known issues: high peak-to-average factor; extra guard interval owing to discontinuity of modulation function; limited number of modulation options. With respect to said above, we believe that data coding enhancement is an actual problem in coherent wireless communications.

Related works. A coherent electromagnetic bearer offers ample opportunities to increase spectral efficiency $\gamma$ of physical channel. The legacy non-coherent DWDM channel with $\Delta F=100 \mathrm{GHz}$ bandwidth and data

(C) V.I. Tikhonov, 2016 
transmission rate $R \approx 10 \mathrm{Gbps}$ shows $\gamma \approx 0.1 \mathrm{~b} / \mathrm{s} / \mathrm{Hz}$. In turn, modern coherent optical systems demonstrate $\gamma \approx 3 \mathrm{~b} / \mathrm{s} / \mathrm{Hz}$ and more [7]. There are two coding methods primarily used in coherent systems: a) Nyquist pulse shaping in time domain; b) Fourier transforms in frequency domain [8]. These two methods are theoretically equivalent due to known relationships between the impulse response function $\eta(t)$ of a linear dynamic system and its Fourier image $g(\omega)$ : $\eta(t) \leftrightarrow g(\omega)$, [9]. In practice, two aforesaid alternatives may counteract for some reasons. The Nyquist shaping requires instant measuring the signal in precise moments, while Fourier equalizer obtains integral characteristics of baseband signal. So, the first approach seems more adequate for stable optic channels, whereas Fourier method is more relevant to radio trunks with chaotic noise impact.

An actual issue remains the channel capacity $C$ estimation [10]. Along with known Shannon-Hartley formula for analogue channel with spread signal spectrum it is estimated due to signal-to-noise ratio (SNR):

$$
C=\Delta F \bullet \log _{2}(1+S N R) \times \text { bps. }
$$

According to (1), the maximal spectral efficiency depends on SNR:

$$
\gamma \rightarrow \frac{C}{\Delta F}=\log _{2}(1+S N R)
$$

The SNR matter is commonly discussed in the context of additive Gaussian noise and non-coherent detection; however, this fundamental result apparently needs rethinking with respect to coherent detection technique. An original method to estimate the capacity limit of fiber-optic communication systems introduced in [11], where physical phenomena and sources of noise reviewed for data transmission over optical fiber, along with the impact of fiber quadratic electro-optic effect (Kerr nonlinearity). The capacity limit estimation proceeds on the basis of ring constellation diagram. Several impairment mitigation techniques introduced to define a fiber channel for the most relevant applications.

The ref [12] presents a sinc-pulse generation method based on direct synthesis a flat comb of phase-locked frequency with out-of-band suppression. Known $\sin c(x)=\frac{\sin (x)}{x}$ function is a product of Dirac delta pulse shaping due to the boxcar spectral filter (so called "sinc-shaped pulse", or "Nyquist pulse"). This waveform is theoretically ideal filter for fast data coding, but not implemented precisely. Thus, a raised cosine filters envisaged to compromise sinc-shaping approach. Along with the time-frequency duality concept, the 
normalized sinc-function $\sin c(x)=\frac{\sin (\pi \cdot x)}{\pi \cdot x}$ maps on Fourier image of normalized boxcar form, i.e. rectangular function:

$$
\operatorname{rect}(z)=\Pi(z)= \begin{cases}0 & \text { if }|z|>0.5 \\ 0.5 & \text { if }|z|=0.5 \\ 1 & \text { if }|z|<0.5\end{cases}
$$

Therefore, the frequency comb corresponds to periodic sinc-pulses, and instead of shaping a single-sinc pulse, a sequence of sinc-pulses can be directly generated by optical frequency comb. It is also concluded in [12] that versus OFDM, Nyquist pulse shaping is less complex and sensitive to fiber nonlinearities, requires lower bandwidth and moderates peak-to-average ratio. However, the fast sinc-shaping with high order modulation is challenging. Recently, the first experimental high speed all optical sinc-pulse generation with time-division multiplexing reported in [13]. Also presented a superNyquist signal generation with optic/electrical spectrum shaping (referred to as Fast-than-Nyquist or FTN), [14]. The FTN signal estimated on maximum likelihood sequence (i.e. maximum a posteriori) where high tolerance shown in 9QAM multi-modulus equalization.

Objectives. Summarizing the cited refs, we note that coherent communication systems are of particular interest both in wireless and wired optical networks. However, despite impressive scientific researches and practical advances in coherent optical communications, no uniformed theoretical method for truly scalable data coding in diverse coherent channels exhibited so far, but two concurrent alternatives based on Nyquist temporal waveform and Fourier spectral mapping.

This work targets substantiation a unified approach on hybrid spectral/temporal data coding in coherent telecommunication channel to provide an extended scalability around diverse wireless and wired physical media.

Following this, a piecewise linear phase modulation method introduced hereinafter for ternary data coding in a coherent channel, deemed wireless network application and beyond.

Basic principles of piecewise linear phase modulation. The proposed method of digital data coding due to piecewise linear phase modulation in coherent channel is based on the following theoretical principles.

1) The permanently constant power provision for generated output signal while data coding proceeding; this causes near the ideal peak-to-average power ratio $(P A R \rightarrow 1)$, and therefore, the minimal technical requirements to 
transceiver linearity and dynamics; in turn, the phase variation of main carrier remains the primarily bearer's property for data transfer execution.

2) Strict temporal phase continuity of the main carrier during all the communication process; this enables the overall regularity of data transmission scenario with no extra guard intervals between adjacent symbols; thus, channel performance can unlimitedly scale towards baud rate variation.

3) Precisely linear character of phase modulation function $\phi(t)$ at any open time interval $t \in(0, \infty)$; this means that the first phase derivative $\phi^{\prime}(t)$ is discrete limited function: $\omega(t)=\phi^{\prime}(t) \in\left[0, \pm \omega_{1}, \pm \omega_{2}, \ldots, \pm \omega_{k}, \ldots, \pm \omega_{K}\right]$ everywhere in $t \in(0, \infty)$, where $\omega(t)$ is angular frequency of baseband signal $\phi(t) ; \omega_{1}, \omega_{2}, \ldots, \omega_{k}, \ldots, \omega_{K}$ are discrete subcarriers measured in " $\mathrm{rad} / \mathrm{s}$ " units within the limited frequency band $\Delta F$; so, the baseband signal $\phi(t)$ is a firstorder smooth function with discrete and compact spectrum allocation:

$$
-\frac{\Delta \mathrm{F}}{2}<f_{k}=\frac{\omega_{k}}{2 \cdot \pi}<+\frac{\Delta F}{2} .
$$

4) Multilayer spectral/temporal data coding of distinct ternary digits for any transferred symbol within the sampling interval $\tau \in(t, t+T)$. On the first layer, solely one ternary digit formed due to the piecewise linear function of phase modulation within the sampling interval $\tau \in(t, t+T)$. In multilayer mode, the sampling interval $T$ is hierarchically segmented in a pyramid of nested time slots, wherein any slot carries a distinct ternary digit of correspondent layer. Respectively, any time slot operates with its own spectral presentation of baseband signal.

Single layer symbol coding with ternary digit presentation. In the simplest case, one layer of data coding used, and therefore, any symbol formed by solely one ternary digit. The figure 1 shows six sampling intervals from $t=0$ to $t=6 T$ wherein six ternary digits of the first layer are coded: $+1,-1$, $0,-1,0,-1$ due to the linear phase variation within the range $|\phi(t)| \leq \frac{\pi}{2}$. The phase signal $\phi(t)$ always begins and ends on the zero phase value (return to zero modulation method, or RTZ). The ternary state of the first layer digit is estimated as an overall assessment on the whole sampling interval $\tau \in(t, t+T)$; herewith, two side harmonics (left and right ones) are generated: $\omega_{1}^{-}=-\frac{\pi}{2}: \frac{T}{2}=-\frac{\pi}{T}$ and $\omega_{1}^{+}=+\frac{\pi}{T}$. 


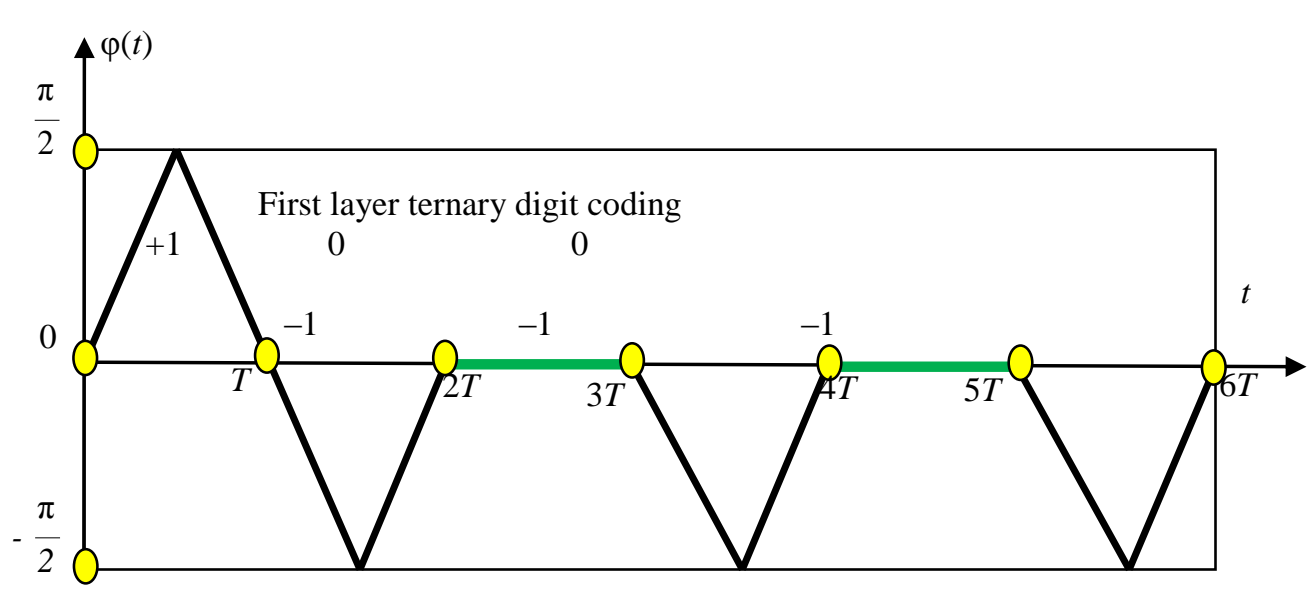

Fig. 1. First layer of data coding with piecewise linear function of phase modulation

The one layer ternary data coding is expedient to minimal transceiver complexity and/or the worst case of signal-to-noise ratio; however, this type of digital data presentation, in contrast to conventional binary data transmission, provides an exhaustive mechanism of serial data stream structuring shaped as formal grammar text which is interpretable by an abstract finite state automaton like Turing machine [15].

As known, Turing machine interprets serial code formed by one or more alphabet letters and one syntax sign (i.e. "space"). The one-letter alphabet based machine is rather primitive and cumbersome implemented; instead, the two-letter formal texts in view of binary scripts are ubiquitously used in modern digital processors and programming languages. For this reason, the ternary coding of digital flow enables comprehensive data processing on the physical layer of communication channel in terms of formal text aware Turing machine. The two states of ternary digit (" $1 "$ and "+ 1") will be interpreted by Turing machine (i.e. channel processor) as conventional binary bit states 0 and 1 , whereas the ternary state "0" understood as syntax sign "space".

We note that even the simplest case of the proposed method for ternary digit coding with solely one layer of symbol presentation significantly extends the scope of coherent signal detection. In fact, the baud rate depends on two variable parameters, i.e. period $T$ and maximal phase deviation $\left|\phi_{\max }\right|$. In fig. 1, the maximal phase deviation assumed $\left|\phi_{\max }\right|=\frac{\pi}{2}$; though, this value can vary in a wide range $0<\left|\phi_{\max }\right|<\propto$. If here the overall bandwidth is fixed $(\Delta F=$ const $)$, then $f$ is limited: 


$$
f_{1}<\frac{\left|\phi_{\max }\right|}{\pi \cdot T} .
$$

On the other hand, if phase derivative module in non-zero digit presentation is fixed (i.e. $\left|\phi^{\prime}(t)\right|=$ const ) then period $T$ depends on $\left|\phi_{\max }\right|$ as it is clear from fig. 1 :

$$
\begin{gathered}
\left\langle\left|\omega_{1}\right|=\left|\phi^{\prime}(t)\right|=\left|\frac{\Delta \phi_{\max }}{0.5 \bullet T}\right|\right\rangle \rightarrow\left\langle\left|2 \bullet \pi \bullet f_{1}\right|=\left|\frac{2 \bullet \Delta \phi_{\max }}{0.5 \bullet T}\right|\right\rangle \rightarrow \\
\left\langle\left|\pi \bullet f_{1}\right|=\frac{1}{T} \bullet\left|\Delta \phi_{\max }\right|\right\rangle \rightarrow\left\langle\pi \bullet\left|f_{1}\right|=f_{S} \bullet\left|\Delta \phi_{\max }\right|\right\rangle \rightarrow \\
\rightarrow f_{S}=\left|f_{1}\right| \bullet\left|\frac{\pi}{\Delta \phi_{\max }}\right| .
\end{gathered}
$$

If $\left|\phi_{\max }\right|=\frac{\pi}{2}$, than $f_{S}=2 \bullet\left|f_{1}\right| ;$ if $\left|f_{1}\right|=\frac{\Delta F}{2}$, then $f_{S}=\Delta F$.

This results in the following formula:

$$
f_{S}=\frac{\Delta F}{2} \bullet\left|\frac{\pi}{\Delta \phi_{\max }}\right|=\Delta F \bullet\left|\frac{\pi}{2 \bullet \Delta \phi_{\max }}\right| .
$$

Define phase modulation factor $m$ :

$$
m=\frac{\left|2 \bullet \Delta \phi_{\max }\right|}{\pi} .
$$

Now we obtain the formula for symbol transmission baud rate:

$$
f_{S}=\frac{\Delta F}{m} .
$$

The related bit rate $R$ is calculated as

$$
R=\log _{2} N_{S} \bullet f_{S}=\log _{2} N_{S} \bullet \frac{\Delta F}{m},
$$

where $N_{S}$ is the number of discrete states in one symbol. If one layer ternary coding used, than 3 states of one digit symbol envisaged:

$$
R_{1}=\log _{2} 3 \bullet \frac{\Delta F}{m} \approx 1.585 \bullet \frac{\Delta F}{m} .
$$


Based on (11), the smooth and accurate channel productivity becomes scalable in a wide range of $0<R<\infty$ due to variation the phase modulation factor $0<m<\infty$.

Conclusion. Advanced coherent communication systems open up new opportunities in wireless and optic network engineering, where impressive achievements exhibited recent years. However, a uniformed theoretical basis for data coding in coherent channels is challenging. Approaching this, a novel method of ternary data coding introduced herein for coherent radio/optic channels due to piecewise linear phase modulation. It is imposed by signal power invariance and baseband signal continuity, along with locally linear phase modulation and multilayer symbol shaping. The simplest case of one layer symbol coding studied in the paper. It is expedient to minimal transceiver complexity and/or the worst case of signal-to-noise ratio, still providing a smart mechanism for channel tuning and comprehensive data processing in terms of formal grammar text which is interpretable by finite state automaton like Turing machine. The given approach aims to contribute researches in next generation networking by increasing performance scalability of the coherent channels in a wide spectrum of wired and wireless applications with particular focus on sensor networks and machine-to-machine systems. Further consideration the algorithms of two- and more layered symbol coding assumed hereinafter beyond this paper.

\section{References:}

1. International Telecommunication Union - Radio communication Sector (2013), "ITU-R FAQ on International Mobile Telecommunications (IMT)", available at: http://www.itu.int/en/ITU-R/Documents/ITU-R-FAQ-IMT.pdf.

2. "Ninth meeting of Working Party 5D on IMT systems" (Chongqing, 13-20 October, 2010), available at: https://www.itu.int/md/R00-SG05-CIR-0020/en.

3. Jansson, K., "First in the world with $4 \mathrm{G}$ ", available at: http://www.teliacompanyhistory. $\mathrm{com} /$ pioneering-the-future/pioneering-the-future/first-in-the-world-with-4g/.

4. GSMA Intelligence (2014), "Understanding 5G: Perspectives on future technological advancements in mobile", available at: https://www.gsmaintelligence.com/ research/?file=141208-5g.pdf\&download.

5. "Architecture of the LTE Air Interface," available at: http://www.cs.nccu.edu.tw/ jang/ teaching/MobileMgt_files/Architecture\%20of\%20the\%20LTE\%20Air\%20Interface.pdf.

6. NXP White paper (2008), "Long Term Evolution Protocol Overview", available at: https://www.nxp.com/files/wireless_comm/doc/white_paper/LTEPTCLOVWWP.pdf.

7. Bertran-Pardo, O. (2013), "Submarine transmissions with spectral efficiency higher than 3 $\mathrm{b} / \mathrm{s} / \mathrm{Hz}$ using Nyquist pulse-shaped channels", Optical Fiber Communication Conference (OFC/NFOEC), 2013.

8. Le Nguyen, Binh (2013), Digital Processing: Optical Transmission and Coherent Receiving Techniques, CRC Press, $507 \mathrm{p}$.

9. Korn, G.A., and Korn, T.M. (2000), Mathematical Handbook for Scientists and Engineers, General Publishing Company, $1151 \mathrm{p}$.

10. Desurvire, E. (2009), Classical and quantum information theory: an introduction for the telecom scientists, Cambridge university press, $688 \mathrm{p}$. 
11. Essiambre, R. (2010), "Capacity limits of optical fiber networks", Journal of Lightwave Technol. No 28 (4), pp. 662-701.

12. Soto, M.A. (2013), "Optical sinc-shaped Nyquist pulses of exceptional quality", Nature Communications 4, available at: http://www.nature.com/articles/ncomms3898.

13. Zhang, J. (2014), "High Speed All Optical Nyquist Signal Generation and Full-band Coherent Detection", available at: https ://www.ncbi.nlm.nih.gov/pmc/articles/PMC4139967/.

14. Zhang J. (2014), "Super-Nyquist signal transmission and digital signal processing", Proc. of the SPIE, Vol. 9267, 2014, 7 pp, available at: http://adsabs.harvard.edu/abs/ 2014SPIE.9267E.0LZ.

15. Turing, A.M. (1950), "Computing machinery and intelligence", available at: https://www.csee.umbc.edu/courses/471/papers/turing.pdf.

Received 16.11.2016

The article is presented by doctor of technical sciences, director of the Institute of Radio, Television and Information Security of "O.S. Popov ONAT" Vasiliu E.V.

Tikhonov Victor, Dr. Tech. Sci., Professor

Odessa National Academy of Telecommunications

Str. Kuznechna, 1, Odessa Ukraine, 65029

Tel.: 067-752-13-90, e-mail: victor.tykhonov@onat.edu.ua 
УДК 621.391

Кусково-лінійна фазова модуляція для кодування трійкових даних у когерентному безпровідному каналі / Тіхонов В.І. // Вісник НТУ "ХПІ". Серія: Інформатика та моделювання. $-2016 .-$ №. .... - Р. ... - ....

У статті представлено новий метод комбінованого частотно-часового кодування послідовних символів у радіоканалі з пакетною комутацією, який здійснюється шляхом безперервної фазової модуляції кусково-лінійними функціями. Описано перший рівень багаторівневого представлення символу трійчастими розрядами Даний метод покращує динамічну адаптацію і розширює можливості масштабування продуктивності каналу. Іл.: 1. Бібліогр.: 15 назв.

Ключові слова: кодування послідовних символів, фазова модуляція, багаторівневого представлення символу, динамічна адаптація.

\section{UDC 621.391}

Piecewise linear phase modulation for ternary data coding in coherent wireless channel / Tikhonov V.I. // Herald of the National Technical University "KhPI". Subject issue: Information Science and Modeling. -2016 . - №. .... - P. ... - ....

The paper introduces the novel method of combined time-frequency successive symbol coding in a packet based radio channel, which is performed due to continuous phase modulation by piecewise linear functions. The first layer of multilayered symbol presentation with ternary digits described. This method improves dynamic performance adaptation of the channel and extends its scalability. Figs.: 1. Refs.: 15 titles.

Keywords: symbol coding, phase modulation, multilayered symbol presentation, dynamic performance adaptation.

\section{УДК 621.391}

Кусочно-линейная фазовая модуляция для кодирования троичных данных в когерентном беспроводном канале / Тихонов В.И. // Вестник НТУ "ХПИ". Серия: Информатика и моделирование. - 2016. - №. 44 (1216). - Р. 136 - 144

В статье представлен новый метод комбинированного частотно-временного кодирования последовательных символов в радиоканале с пакетной коммутацией, который осуществляется путем непрерывной фазовой модуляции кусочно-линейными функциями. Описан первый уровень многоуровневого представления символа троичными разрядами. Данный метод улучшает динамическую адаптацию и расширяет возможности масштабирования производительности канала. Ил.: 1. Библиогр.: 15 назв.

Ключевые слова: кодирование последовательных символов, фазовая модуляция, многоуровневое представление символа, динамическая адаптация. 